\title{
Risk Factors and Causes of Male Infertility-A Review
}

Roshan Kumar Mahat ${ }^{1^{*}}$, Manisha Arora ${ }^{2}$, Dhananjay Vasantrao Bhale ${ }^{3}$, Shrirang Holkar ${ }^{3}$, Sudeep Kumar ${ }^{4}$ and Tapeshwar Yadav $^{5}$

${ }^{1}$ Department of Biochemistry, GR Medical College, Gwalior, India

${ }^{2}$ Department of Biochemistry, Muzaffarnagar Medical College, Muzaffarnagar, India

${ }^{3}$ Department of Biochemistry, MGM's Medical College, Aurangabad, India

${ }^{4}$ Department of Biochemistry, Santosh Medical College, Ghaziabad, India

${ }^{5}$ Department of Biochemistry, Nobel College, Sinamangal, Kathmandu, Nepal

“Corresponding author: Roshan Kumar Mahat, Ph. D. Research Scholar, Department of Biochemistry, GR Medical College, Gwalior, India, Tel: 07417905474; E-mail: mahatroshan79@gmail.com

Rec date: March 18, 2016; Acc date: May 05, 2016; Pub date: May 09, 2016

Copyright: ( 2016 Mahat RK, et al. This is an open-access article distributed under the terms of the Creative Commons Attribution License, which permits unrestricted use, distribution, and reproduction in any medium, provided the original author and source are credited.

\begin{abstract}
Infertility is defined as inability to achieve conception in a period of one year in a couple, despite regular and adequate unprotected sexual intercourse. A male is said to be infertile if he is unable to impregnate his partner after one year of unprotected intercourse. It is an important medical and social problem in the world as regards $15 \%$ of couples are infertile and $40 \%$ are infertile because of male factor infertility. This review highlights the risk factors and some causes that are responsible for male infertility. The aim of this review is to generate information which could help in the evaluation of male infertility.
\end{abstract}

Keywords: Male infertility; Obesity; Smoking; Varicocele; Endocrinal disorders

\section{Introduction}

Following regular and frequent unprotected sexual intercourse, about $84 \%$ of couples in general population are expected to conceive within one year and about $92 \%$ should conceive within two years. When a couple fails to conceive even after two years of regular frequent coitus and there is no known reproductive pathology, the couple may be considered infertile [1]. However, the term infertility implies a definitive inability to conceive. Therefore, couples who do not conceive in more than one year should be regarded as sub-fertile. According to this definition, approximately $14 \%$ of the couples are sub-fertile. To be more exact, the term sub-fertile means a male who failed to conceive after one year of regular unprotected intercourse with the same partner and who had a sperm count of less than 20 million/ml [2]. Infertility has increased as a problem over the last thirty years all over the world, regarding to social phenomena, such as the tendency for marriage at a later age and child bearing, increasing use of contraception specially Intrauterine device and liberalized abortion [3].

The incidence of infertility in a population has important demographic and health implications [3]. The prevalence of infertility varies widely, being less in developed countries and more in developing countries where limited resources for investigation and treatment are available [4]. Infertility is an important medical and social problem in the world as regards $15 \%$ of couples are infertile and $40 \%$ are infertile because of male factor infertility and $40 \%$ are because of female factor infertility and in the remainder both factors are associated [5]. Infertility is a worldwide problem and approximately $8-10 \%$ of couples within reproductive age group are infertile. It is estimated that globally 60-80 million couples suffer from infertility every year, of which probably between 15-20 million are in India alone [6]. Infertility is a common gynaecological problem affecting $15 \%$ of couples attempting their first pregnancy, in which cases it is called primary infertility; while those with secondary infertility are about $10 \%$ of the population. Secondary infertility could be as high as $52 \%$ in some sub-Sahara African countries and as low as $23 \%$ in some Asian countries [7].

\section{Risk Factors of Male Infertility}

\section{Age}

Blood testosterone levels decline with age in most men, even in those who are healthy, and this decline probably begins around the age of thirty [8]. The decline of around 1\% per year in testosterone levels after the age of 30 years has been termed the andropause [9]. However, a more technically accurate description for the decline in testosterone might be "symptomatic hypogonadism in aging males." Hypogonadism is not defined by any specific level of serum androgens because the testosterone level that causes dysfunction varies widely among individuals [10]. The symptoms associated with symptomatic hypogonadism in aging males include decreased libido, decreased muscle mass, decreased bone mineral density, increased fat mass, central obesity, insulin resistance, emotional irritability, dysphoria and erectile dysfunction [11]. The risk of becoming infertile doubled in men who are over 35 years old compared with men who are under 25 years old, and five times longer to conceive at the age of 45 years [11]. In a study on a convenient sample of fifty five healthy men ranging in age from 52 to 79 years old compared with a control group of men less than 52 years old found that older men had lower semen volume, with abnormal sperm morphology and reduced vitality [12]. A study in Belgium by Mahmoud et al. showed that testicular volume of elderly males in their eighth decade was significantly less with $31 \%$ when compared with the young control group of 18 to 40 years old [13].

\section{Smoking}

Smoking can decrease male fertility by decreasing the sperm motility and percentage of normal sperm cells, and that a decrease in 
Page 2 of 5

the percentage of motility of sperm cells and normal morphology is correlated with the number of cigarettes smoked per day [14]. Smoking has also been linked with an increase in reactive oxygen species levels, leading to oxidative stress in the environment. This oxidative stress may exceed the antioxidant capacity of seminal plasma and can be toxic for sperm, causing oxidative damage [14]. One of the studies revealed that smoking leads to a decrease in semen parameters such as viability, sperm concentration, motility and morphology [15].

\section{Obesity}

Several studies have shown that fertility decreased in overweight and obese women $[16,17]$. Similarly, obesity may play a role in men fertility. A study in United State investigating farmers and their wives showed that $10 \mathrm{~kg}$ increase in the body weight may reduce fertility by nearly $10 \%$, and the great effect for men with a body mass index (BMI) of more than 32 [18]. A significant reduction in the number of normal motile sperm has been observed among men with BMI over 25, it also found that men with excess fat in the thigh and suprapubic area have poor semen quality [19]. A Norwegian cohort study found that the risk of infertility is associated not only with high body mass index (BMI) but also with low BMI [20].

\section{Occupational exposure}

Among the factors thought to affect male infertility is the occupational exposure, it was found that there is no significant association between infertility and occupational exposure [21]. Another study conducted in Lebanon had demonstrated that occupational exposure to harmful physical and chemical agents is associated with increased risk of male infertility [22]. Exposure to organic solvents at work associated with reduction in count of motile sperm [23], a number of solvents that are used in industry may have an adverse effect on male reproductive function like carbon disulphide that had shown to affect semen quality but in low exposures had shown no effect [24]. Previous exposure to glycol ethers in work place associated with decrease in the semen quality [25]. Semen quality in workers exposed occupationally to hydrocarbons like toluene, benzene and xylene present anomalies, including alterations in viscosity, liquefaction capacity, sperm count, sperm motility, and the proportion of sperm with normal morphology compared with unexposed males [26]. Furthermore, welding may reduce the quality and quantity of semen, likewise, occupations in which the workers exposed to heat they have reduced sperm count. Also workers in agriculture or in a pesticide factory may experience a negative affect on reproduction, Dibromochloropropane can cause testicular toxicity and reduce sperm production. In men who exposed to Ethylene Di-Bromide had decreased sperm count and increase number of abnormal sperm, also insecticide have been found to have decreased sperm motility but there is no effect on fertility [25]. Dichlorodiphenyltrichloroethane is a type of pesticides can lead to decreased fertility and altered sperm counts [27]. Industrial and construction workers presents with an increase infertility rates because of greater exposure to stress [27], occupational stress was negatively correlated with the proportion of normal sperm [25]. Heavy metals like cadmium and lead reduce the quality of semen, mercury can concentrate in the testes beside other organs, mercury poisoning leads to infertility. Furthermore, mercury and copper can interfere in spermatogenesis [27].

\section{Exercise}

There are many health benefits of exercise, despite of that there are a conflict results about the effect of exercise on the male reproductive function. It was found that endurance training at highest level does not alter the male reproductive function, and there is no significant effect in hormonal profile and sperm parameters except for sperm motility in the cyclist (riding a bicycle) it was observed lower sperm motility but that may attributed to physical factors [28]. The effect of vicious cycling was studied in another study and it was found that infertility was from the less common symptoms [29]. But recent study suggesting that long term strenuous exercise have a deleterious effect on semen parameters [30], and also resistance exercise shows a significant decline in free and total testosterone [31].

\section{Diet (Alcohol and caffeinated beverages)}

Alcohol consumption affects the reproductive system at all levels [32]. Drinking caffeinated beverages may interfere with fertility in men; a study showed that men who consume more than three cups of tea daily is associated with decreased fertility [33].

\section{Electronic devices}

Exposure for a long time on a laptop will increase the scrotal temperature and have a negative impact on sperm parameters [34]. Furthermore, using cell phones has been noted to have an adverse effect on male fertility due to decreased semen quality which paralleled of daily exposure to cell phones [35]. Another study found that use of cell phones decreased the actual percentage of the live sperm and this correlated with the duration of using cell phones [36].

\section{Stress}

Most studies have rejected the theory of stress as the only factor in the etiology of infertility; but there is growing evidence to show that stress is an additional risk factor for infertile. Semen parameters are significantly decreased in men who are under stress [37]. Many forms of stress including psychological can affect male fertility and reproduction. The autonomic nervous system and the adrenal hormones participate in the classic stress response while also affecting the reproductive system [38].

\section{Scrotal temperature}

Types of undertrousers affect the scrotal temperature, and semen quality. Wearing tight fitting undertrousers is associated with increased scrotal temperature. Also the position or activity has its impact on increasing the scrotal temperature, walking is associated with significantly lower scrotal temperature than sitting [39]. Driving for more than two hours continuously is associated with increasing the scrotal temperature [40]. Spermatogenesis, especially differentiation and maturation of spermatocytes and spermatids, is temperature dependent requiring a temperature of at least $1^{\circ} \mathrm{C}$ to $28^{\circ} \mathrm{C}$ below core body temperature $[41,42]$. This is supported by studies in humans that artificially brought testicles near or into the inguinal canal and induced high scrotal and consequently testicular temperatures near core body temperature [43-46]. Consequently, spermatogenesis was impaired and semen quality reduced. 


\section{Reactive Oxygen Species (ROS)}

Reactive oxygen species have negative effect on sperm parameter. The sperm plasma membrane is very sensitive to the effect of ROS since it contains abundant unsaturated fatty acids. The presence of high ROS levels in the semen implies an imbalance between ROS production and the antioxidant system. Increased ROS level can lead to damage with subsequent sperm dysfunction or cell death. These free radical or oxidative damage to sperm is thought to be responsible for many cases of idiopathic oligospermia. Men exposed to increased levels of sources of free radicals are much more likely to have abnormal sperm and sperm counts [47].

\section{Therapeutic drugs}

Primary infertility may results from the use of various drugs. This phenomenon may be the result of an effect on the hypothalamicpituitary- gonadal axis or a direct toxic effect on the gonads. Some of the drugs are antineoplastic agents (cyclophosphamide, chlorambucil, busulphan, and methotrexate), glucocorticosteroids, hormonal steroids (diethylstilbestrol, medroxyprogesterone acetate, estrogen, and the constituents of oral contraceptives), antibiotics (sulfasalazine and cotrimoxazole), thyroid supplements, spironolactone, cimetidine, colchicine, marijuana, opiates, and neuroleptic agents [47].

\section{Causes of Male Infertility}

\section{Varicocele}

Varicocele is a dilation of testicular veins within pampiniform plexus of spermatic code that holds up a man's testicles. Varicoceles are the leading correctable cause of infertility in men who present to an infertility clinic for evaluation [48]. According to human report update (2001) varicocele is found in $15 \%$ of general population including adolescents and adults [48] but the prevalence of varicocele among men attending the infertility clinics range between 30-40\% [49]. Varicocele occurs most commonly on left side. The etiology of varicocele is multifactorial, the most common is the difference in the anatomy of the left and right spermatic vein, absence of valves in the spermatic vessels resulting in retrograde of blood flow and compression of the left renal vein causing a partial obstruction [50].

\section{Endocrinal disorders}

Endocrine causes of male infertility are often referred as pretesticular causes. Impairment of fertility in these cases is secondary to either a hormone deficiency or an excess [51]. Hormonal disturbances are result in approximately $15 \%$ of married couples and males are responsible in about $50 \%$ of them. Fertility in men required normal functioning of the hypothalamus, pituitary glands and testes and the complete male germ cell development is dependent on the balanced endocrine secretion of these glands [52]. Abnormalities in hormone production may be a factor in male infertility. Hypogonadotrophic hypogonadism which is the failure of pituitary gland to produce adequate amounts of follicle stimulating hormone and luteinizing hormone can lead to decreased sperm count and a state of infertility [53]. Hyperprolactinemia causes infertility in around $11 \%$ of oligospermic males. Hyperprolactinemia inhibits the pulsatile secretion of the gonadotrophin releasing hormone, which causes decreased pulsatile release of follicle stimulating hormone, lutenizing hormone and testosterone, which in turn causes spermatogenic arrest, impaired sperm motility and altered sperm quality. It later produces secondary hypogonadism and infertility [54]. Since spermatogenesis occurs in close contact with the sertoli cells, the thyroid hormones must exert significant regulatory role in sperm production. Therefore disturbances in the thyroid function could affect spermatogenesis and male fertility [55].

\section{Male reproductive tract infection}

Infections of the male reproductive tract is a common disese that can deteriorate the quality of spermatozoa and impair the function of male accessory gland; for this reason it is considered one of the potentially correctable causes of male infertility. Infection of the male reproductive tract significantly decreases the levels of semen volume, a-glucosidase, fructose and zinc in seminal plasma suggesting impairment of the secretary function of the epididymis, seminal vesicles and prostate [56].

\section{Ejaculatory disorders}

Ejaculation consists of the coordinated deposition of semen into the prostatic urethra (emission), closure of bladder neck and contraction of the periurethral and pelvic floor muscles causing expulsion of the semen through the urethra (ejaculation). The process of ejaculation is dependent on central and peripheral nervous system control. Abnormalities of ejaculation can lead to lack of emission ejaculation and retrograde ejaculation and may be caused by neurologic, anatomic and psychologic conditions. Retrograde ejaculation is caused by incomplete closure of the bladder neck. Diabetes mellitus causes peripheral nervous system injury resulting in possible retrograde ejaculation or anejaculation. Central nervous system lesion such as spinal cord injury and myelodysplasia can also cause ejaculatory dysfunction. Some medications like $\alpha$ - blockers, antidepressants, antipsychotics and antihypertensive can also affect ejaculation. Anatomic causes of ejaculatory dysfunction include obstruction of ejaculatory ducts and prior surgery on the bladder neck leading to retrograde ejaculation [57].

\section{Immunological factor}

Antisperm antibodies are found in about 9-33\% of infertile couple. In $8-19 \%$ of these couples, the antibodies are present in man and in $1-21 \%$ antisperm antibodies are contributed by the female partner. Risk factors for the formation of antisperm antibodies in man include vasectomy and epididymitis, although the exact cause for formation of antisperm antibodies is frequently unclear. Antisperm antibodies may decrease fertility potential at several critical points that are important to natural conception. They also cause sperm cells to agglutinate, hindering sperm motility. Sperm penetration through cervical mucus is also impaired. Sperm with antisperm antibodies also have poor sperm egg interactions. The acrosome reaction and zona pellucida binding may be impaired, which in turn may decrease overall fertility potential [57].

\section{Genetic and chromosomal defects}

Genetic causes account for $10-15 \%$ of severe male infertility, including chromosomal aberrations and single gene mutations [58]. A genetic disorder may alter spermatogenesis, impair normal development of the genital tract and decrease sperm motility and fertilization capacity, any of which may lead to varying degrees of male subfertility or infertility [57]. 


\section{Unknown cause}

Infertility of unknown origin includes unexplained male infertility and idiopathic male infertility; it is a condition in which fertility impairment occurs spontaneously or due to an obscure or unknown cause. Infertility of unknown origin accounts for $37 \%$ to $58 \%$. Men classified as having idiopathic male infertility have an unexplained reduction in semen quality with no history associated with fertility problems and have normal findings on physical examination and endocrine laboratory testing [59]. The unexplained forms of male infertility may be caused by several factors, such as chronic stress, endocrine disruption due to environmental pollution, reactive oxygen species and genetic abnormalities [60].

\section{Conclusion}

There are various risk factors and causes that are responsible for infertility in males and these factors should be considered in the treatment of male infertility.

\section{References}

1. Ayaz K, Miah MT, Ahasan HN, Raihan MR, Islam MA, et al. (2012) Male infertility-A review. J Med 13: 190-199.

2. Khan MS, Ali I, Tahir F, Khan GM (2008) Simultaneous analysis of the three hormones involved in spermatogenesis and their interrelation ratios. Pak J Pharm Sci 21: 344-349.

3. Aflatoonian A, Seyedhassani SM, Tabibnejad N (2009) The epidemiological and etiological aspects of infertility in Yazd province of Iran. Iranian J Reprod Med 7: 117-122.

4. Ahmed GA, Hasan HG, Rashid AO (2012) Serum levels of male oligospermia glycoconjugate inhibin $B$ hormone and $a$-L-fucose in Kurdistani (Iraq) populations. Int J Basic Appl Sci 12: 59-66.

5. Al-Rekabe BKK, Al-Wayelli DAOJ, Khadim AHA (2010) Evaluation of serum FSH, LH and testosterone levels in infertile patients affected with different male infertility factors after IUI technique. Thi-Qar Med J 4: 37-46.

6. Mehrotra A, Katiyar DK, Agarwal A, Das V, Pant KK (2013) Role of total antioxidant capacity and lipid peroxidation in fertile and infertile men. Biomed Res 24: 347-352.

7. Jimoh AAG, Olawuyi TS, Omotoso GO, Oyewopo AO, Dare JK (2012) Semen parameters and hormone profile of men investigated for infertility at Midland Fertility Centre, Ilorin, Nigeria. J Basic Appl Sci 8: 110-113.

8. Pasqualotto FF, Lucon AM, Hallak J, Pasqualotto EB, et al. (2004) Risks and benefits of hormone replacement therapy in older men. Rev Hosp Clin Fac Med Sao Paulo 59: 32-38.

9. Feldman HA, Goldstein I, Hatzichristou DG, Krane RJ, McKinlay JB (1994) Impotence and its medical and psychosocial correlates: results of the Massachusetts Male Aging Study. J Urol 151: 54-61.

10. Bhasin S, Cunningham GR, Hayes FJ, Alvin MM, Peter JS, et al. (2006) Testosterone therapy in adult men with androgen deficiency syndromes: an endocrine society clinical practice guideline. J Clin Endocrinol Metab 91: 1995-2010.

11. Pasqualotto FF, Borges JE, Pasqualotto EB (2008) The male biologica clock is ticking: a review of the literature. Sao Paulo Med J 126: 197-201.

12. Ng KK, Donat R, Chan L, Lalak A, Di Pierro I, et al. (2004) Sperm output of older men. Hum Reprod 19: 1811-1815.

13. Mahmoud AM, Goemaere S, El-Garem Y, Van Pottelbergh I, Comhaire $\mathrm{FH}$, et al. (2003) Testicular volume in relation to hormonal indices of gonadal function in community-dwelling elderly men. J Clin Endocrinol Metab 88: 179-184.

14. Nadeem F, Fahim A, Bugti S (2012) Effects of cigarette smoking on male infertility. Turk J Med Sci 42: 1400-1405.
15. Kunzle R, Mueller MD, Hanggi W, Birkhauser MH, Drescher H, et al. (2003) Semen quality of male smokers and non-smokers in infertile couples. Fertil Steril 79: 287-291.

16. Law GDC, Maclehose RF, Longnecker MP (2007) Obesity and time to pregnancy. Hum Reprod 22: 414-420.

17. Bolúmar F, Olsen J, Rebagliato M, Sáez-Lloret I, Bisanti L (2000) Body mass index and delayed conception: a European Multicenter Study on Infertility and Subfecundity. Am J Epidemiol 151: 1072-1079.

18. Sallmén M, Sandler DP, Hoppin JA, Blair A, Baird DD (2006) Reduced fertility among overweight and obese men. Epidemiol 17: 520-523.

19. Kort HI, Massey JB, Elsner CW, Mitchell-Leef D, Shapiro DB, et al. (2006) Impact of body mass index values on sperm quantity and quality. J Androl 27: 450-452.

20. Nguyen RH, Wilcox AJ, Skjaerven R, Baird DD (2007) Men's body mass index and infertility. Hum Reprod 22: 2488-2493.

21. Gracia CR, Sammel MD, Coutifaris C, Guzick DS, Barnhart KT (2005) Occupational exposures and male infertility. Am J Epidemiol 162: 729-733.

22. Inhorn MC, King L, Nriagu JO, Kobeissi L, Hammoud N, et al. (2008) Occupational and environmental exposures to heavy metals: risk factors for male infertility in Lebanon?. Reprod Toxicol 25: 203-212.

23. Cherry N, Labrèche F, Collins J, Tulandi T (2001) Occupational exposure to solvents and male infertility. Occup Environ Med 58: 635-640.

24. Multigner L, Ben BE, Arnaud I, Haguenoer JM, Jouannet P, et al. (2007) Glycol ethers and semen quality: a cross-sectional study among male workers in the Paris Municipality. Occup Environ Med 64: 467-473.

25. Jensen TK, Bonde JP, Joffe M (2006) The influence of occupational exposure on male reproductive function. Occup Med 56: 544-553.

26. Ten J, Mendiola J, Torres-Cantero AM, Moreno-Grau JM, Moreno-Grau S, et al. (2008) Occupational and lifestyle exposures on male infertility: A mini review. Open Reprod Sci J 1: 16-21.

27. Queiroz EK, Waissmann W (2006) Occupational exposure and effects on the male reproductive system. Cad Saude Publica 22: 485-493.

28. Lucía A, Chicharro JL, Pérez M, Serratosa L, Bandrés F, et al. (1996) Reproductive function in male endurance athletes: sperm analysis and hormonal profile. J Appl Physiol 81: 2627-2636.

29. Leibovitch I, Mor Y (2005) The vicious cycling: bicycling related urogenital disorders. Eur Urol 47: 277-286.

30. Safarinejad MR, Azma K, Kolahi AA (2009) The effects of intensive, longterm treadmill running on reproductive hormones, hypothalamuspituitary-testis axis, and semen quality: a randomized controlled study. J Endocrinol 200: 259-271.

31. Tremblay MS, Copeland JL, Van HW (2004) Effect of training status and exercise mode on endogenous steroid hormones in men. J Appl Physiol 96: 531-539.

32. Emanuele MA, Emanuele NV (1998) Alcohol's effects on male reproduction. Alcohol Health \& Research World 22: 195-201.

33. Curtis KM, Savitz DA, Arbuckle TE (1997) Effects of cigarette smoking, caffeine consumption, and alcohol intake on fecundability. Am J Epidemiol 146: 32-41.

34. Sheynkin Y, Jung M, Yoo P, Schulsinger D, Komaroff E (2005) Increase in scrotal temperature in laptop computer users. Hum Reprod 20: 452-455.

35. Agarwal A, Deepinder F, Sharma RK, Ranga G, Li J (2008) Effect of cell phone usage on semen analysis in men attending infertility clinic: an observational study. Fertil Steril 89: 124-128.

36. Wdowiak A, Wdowiak L, Wiktor H (2007) Evaluation of the effect of using mobile phones on male fertility. Ann Agric Environ Med 14: 169-172.

37. Collodel G, Moretti E, Fontani V, Rinaldi S, Aravagli L, et al. (2008) Effect of emotional stress on sperm quality. Indian J Med Res 128: 254-261.

38. Mishra RK, Verma HP, Singh N, Singh SK (2012) Male infertility: lifestyle and oriental remedies. J Sci Res 56: 93-101.

39. Jung A, Leonhardt F, Schill WB, Schuppe HC (2005) Influence of the type of undertrousers and physical activity on scrotal temperature. Hum Reprod 20: 1022-1027. 
Citation: Mahat RK, Arora M, Bhale DV, Holkar S, Kumar S, et al. (2016) Risk Factors and Causes of Male Infertility-A Review. Biochem Anal

40. Bujan L, Daudin M, Charlet JP, Thonneau P, Mieusset R (2000) Increase in scrotal temperature in car drivers. Hum Reprod 15: 1355-1357.

41. Chowdhury AK, Steinberger E (1970) Early changes in the germinal epithelium of rat testes following exposure to heat. J Reprod Fertil 22: 205-212.

42. Thonneau P, Bujan L, Multigner L, Mieusset R (1998) Occupational heat exposure and male fertility: a review. Hum Reprod 13: 2122-2125.

43. Mieusset R, Bujan L, Mansat A, Pontonnier F, Grandjean H (1987) Hyperthermia and human spermatogenesis: enhancement of the inhibitory effect obtained by 'artificial cryptorchidism'. Int J Androl 10: 571-580.

44. Shafik A (1991) Testicular suspension as a method of male contraception: technique and results. Adv Contr Deliv Syst 7: 269-279.

45. Moeloek N (1995) Polyester sling scrotal cover induces oligozoospermia in normal Indonesian men. Med J Indones 4: 225-230.

46. Mieusset R, Bujan L (1994) The potential of mild testicular heating as a safe, effective and reversible contraceptive method for men. Int J Androl 17: 186-191.

47. Olayemi FO (2010) A review on some causes of male infertility. Afr J Biotechnol 9: 2834-2842.

48. Cozzolino DJ, Lipshultz LI (2001) Varicocele as a progressive lesion: positive effect of varicocele repair. Hum Reprod Update 7: 55-58.

49. Jarow JP (2001) Effects of varicocele on male fertility. Hum Reprod Update 7: 59-64.

50. Naughton CK, Nangia AK, Agarwal A (2001) Varicocele and male infertility: part II Pathophysiology of varicoceles in male infertility. Hum Reprod Update 7: 473-481.
51. Lalitha C, Sayee R, Jeyanthi K, Shubha R (2013) Hormonal factors associated with hypogonadism and infertility in males - chromosomal abnormality. J Dent Med Sci 10: 71-75.

52. Al-Faisal AHM (2010) Hormonal disturbances among the infertile men in Baghdad-Iraq. J Med Tech Assoc Thailand 38: 3060-3066.

53. Al-Daghistani H, Abdel-Dayem M (2006) Hyperprolactinemia and hypergonadotropins in infertile males with severe oligospermia and azoospermia. The Internet J Endocrinol 3.

54. Singh P, Singh M, Cugati G, Singh AK (2011) Hyperprolactinemia: An often missed cause of male infertility. J Hum Reprod Sci 4: 102-103.

55. Singh R, Hamada AJ, Agarwal A (2011) Thyroid hormones in male reproduction and fertility. Open Reprod Sci J 3: 98-104.

56. Marconi M, Pilatz A, Wagenlehner F, Diemer T, Weidner W (2009) Impact of infection on the secretory capacity of the male accessory glands. Int Braz J Urol 35: 299-309.

57. Brugh VM, Lipshultz LI (2004) Male factor infertility: evaluation and management. Med Clin North Am 88: 367-385.

58. Ferlin A, Arredi B, Foresta C (2006) Genetic causes of male infertility Reprod Toxicol 22: 133-141.

59. Hamada A, Esteves SC, Agarwal A (2011) Unexplained male infertility: potential causes and management. Hum Androl 1: 2-16.

60. Dohle GR, Colpi GM, Hargreave TB, Papp GK, Jungwirth A, et al. (2005) EAU guidelines on male infertility. Eur Urol 48: 703-711. 